\title{
Defibrillator shocks and their impact on objective and subjective patient outcomes: results from the painfree SST clinical trial
}

Sears, Samuel F ; Rosman, Lindsey ; Sasaki, Shingo ; Kondo, Yusuke ; Sterns, Laurence D ; Schloss, Edward J ; Kurita, Takashi ; Meijer, Albert ; Raijmakers, Judith ; Gerritse, Bart ; Auricchio, Angelo

\begin{abstract}
BACKGROUND: The impact of ICD shock on device-measured activity and patient reported outcomes is unknown. OBJECTIVE: The purpose of this study was to analyze the acute and long-term effects of ICD shock on objective behavioral data (i.e., device-based physical activity) and subjective patient reported outcomes (e.g., quality of life and shock anxiety). METHODS: The PainFree SST clinical trial included 2,770 patients with a single or dual-chamber ICD, or cardiac resynchronization defibrillator (CRT-D) who were followed for $22 \pm 9$ months. Participants completed measures of quality of life (EuroQol 5-D [EQ5D]) and shock anxiety (Florida Shock Anxiety Scale [FSAS]) at baseline, bi-annual visits, and monthly for 6 months following an ICD shock. Daily physical activity data were obtained from a built-in device accelerometer. RESULTS: Average daily activity was $185.3 \pm 119.4$ minutes/day. Activity was significantly reduced after an ICD shock $(\mathrm{p}<0.0001)$ and recovered to a normal level after approximately 90 days. ICD shock was also associated with decreased quality of life (EQ5D Health Score) and increased EQ5D anxiety scores, but it did not impact mobility, self-care, activity, or pain. Similarly, shock anxiety (FSAS) increased in shocked patients and remained significantly elevated at 24 months, regardless of appropriate or inappropriate shock delivery. CONCLUSIONS: ICD shocks have a long-lasting, adverse impact on both objective, device-measured physical activity and subjective patient reported outcomes of quality of life and shock anxiety. Successful management of ICD patients requires attention to clinically relevant behavioral and psychological outcomes to expedite recovery and return to activities of daily living.
\end{abstract}

DOI: https://doi.org/10.1016/j.hrthm.2017.12.026

Posted at the Zurich Open Repository and Archive, University of Zurich

ZORA URL: https://doi.org/10.5167/uzh-146016

Journal Article

Accepted Version

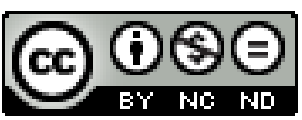

The following work is licensed under a Creative Commons: Attribution-NonCommercial-NoDerivatives 4.0 International (CC BY-NC-ND 4.0) License.

Originally published at:

Sears, Samuel F; Rosman, Lindsey; Sasaki, Shingo; Kondo, Yusuke; Sterns, Laurence D; Schloss, Edward J; Kurita, Takashi; Meijer, Albert; Raijmakers, Judith; Gerritse, Bart; Auricchio, Angelo (2018). Defib- 
rillator shocks and their impact on objective and subjective patient outcomes: results from the painfree SST clinical trial. Heart Rhythm, 15(5):734-740.

DOI: https://doi.org/10.1016/j.hrthm.2017.12.026 


\section{Accepted Manuscript}

Defibrillator Shocks and their Impact on Objective and Subjective Patient Outcomes: Results from the PainFree SST Clinical Trial

Samuel F. Sears, PhD, Lindsey Rosman, PhD, Shingo Sasaki, MD, PhD, Yusuke Kondo, MD, PhD, Laurence D. Sterns, MD, Edward J. Schloss, MD, Takashi Kurita,

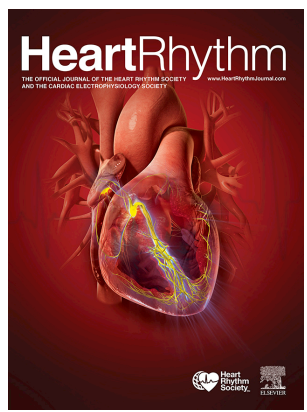
MD, Albert Meijer, MD, Judith Raijmakers, PhD, Bart Gerritse, PhD, Angelo Auricchio, MD

PII: S1547-5271(17)31460-1

DOI: 10.1016/j.hrthm.2017.12.026

Reference: HRTHM 7435

To appear in: Heart Rhythm

Received Date: 1 July 2017

Please cite this article as: Sears SF, Rosman L, Sasaki S, Kondo Y, Sterns LD, Schloss EJ, Kurita T, Meijer A, Raijmakers J, Gerritse B, Auricchio A, Defibrillator Shocks and their Impact on Objective and Subjective Patient Outcomes: Results from the PainFree SST Clinical Trial, Heart Rhythm (2018), doi: 10.1016/j.hrthm.2017.12.026.

This is a PDF file of an unedited manuscript that has been accepted for publication. As a service to our customers we are providing this early version of the manuscript. The manuscript will undergo copyediting, typesetting, and review of the resulting proof before it is published in its final form. Please note that during the production process errors may be discovered which could affect the content, and all legal disclaimers that apply to the journal pertain. 
Samuel F. Sears, $\mathrm{PhD}^{*}$, Lindsey Rosman, $\mathrm{PhD}^{*}$, Shingo Sasaki, MD, PhD ${ }^{\dagger}$, Yusuke Kondo,

MD, PhD ${ }^{\ddagger}$, Laurence D. Sterns, MD ${ }^{\S}$, Edward J. Schloss, MD ${ }^{\prime \prime}$, Takashi Kurita, MD ${ }^{\#}$, Albert

Meijer, $\mathrm{MD}^{* *}$, Judith Raijmakers, $\mathrm{PhD}^{\dagger \dagger}$, Bart Gerritse, $\mathrm{PhD}^{\dagger \dagger}$, Angelo Auricchio, $\mathrm{MD}^{\ddagger \star}$

*Departments of Psychology and Cardiovascular Sciences, East Carolina University, Greenville, NC; ${ }^{\dagger}$ Hirosaki University School of Medicine, Hirosaki, Japan; Chiba University Graduate School of Medicine, Chiba, Chiba, Japan; ${ }^{\S}$ Vancouver Island Arrhythmia Clinic, Victoria, BC, Canada; "The Christ Hospital/The Ohio Heart \& Vascular Center, Cincinnati, OH; "Kinki University School of Medicine, Osaka, Japan; ${ }^{* *}$ Catharina

\section{Correspondence:}

Samuel F. Sears, Ph.D.

17 East Carolina University

18 Department of Psychology

19 Rawl Bldg 104

20 Greenville, NC 27858

21 Phone: (252) 328-6118

22 Fax: (252) 328-6283

23 Email: SearsS@ecu.edu

Short title: ICD Shock and Objective and Subjective Patient Outcomes

Conflict of interest: Statistical support for this study was provided by Medtronic. No

\section{Disclosures:}

Samuel F. Sears, PhD: Honoraria/Consulting Fees: Medtronic, Boston Scientific, funds are directed to East Carolina University. Lindsey Rosman, PhD: None. 
36 Yusuke Kondo, MD, PhD: Speaker's Bureau: Medtronic, St. Jude Medical, Biotronik;

37 Research Grants: St. Jude Medical

38 Laurence D. Sterns, MD: Speaker's Bureau: Boehringer Ingelheim, Pfizer, Bayer, BMS

39 Edward J. Schloss, MD: Honoraria/Consulting Fees: Medtronic, Boston Scientific; Equity

40 Interests/Stock Options (Non-Public): AliveCor

41 Takashi Kurita, MD: Speaker's Bureau: Biotronik, Boston Scientific, Medtronic, St. Jude

42 Medical

43 Albert Meijer, MD: Honoraria/Consulting Fees: Medtronic, Biosense

44 Judith Raijmakers, PhD: Employment: Medtronic

45 Bart Gerritse, PhD: Employment: Medtronic

46 Angelo Auricchio, MD: Honoraria/Consulting Fees: Abbott, Biosense Webster, Bristol-

47 Myers Squibb, Boston Scientific, Cardiotek-Schwarzer, Cordis Biologics Delivery Systems,

48 DC Devices, Leadexx, Medtronic, Resmed, Respicardia, Schiller AG, Sorin Group, St. Jude

49 
51 Abstract

52 Background: The impact of ICD shock on device-measured activity and patient reported

53 outcomes is unknown.

54 Objective: The purpose of this study was to analyze the acute and long-term effects of ICD

55 shock on objective behavioral data (i.e., device-based physical activity) and subjective patient

56 reported outcomes (e.g., quality of life and shock anxiety).

57 Methods: The PainFree SST clinical trial included 2,770 patients with a single or dualchamber ICD, or cardiac resynchronization defibrillator (CRT-D) who were followed for 22 \pm 9 months. Participants completed measures of quality of life (EuroQol 5-D [EQ5D]) and shock anxiety (Florida Shock Anxiety Scale [FSAS]) at baseline, bi-annual visits, and monthly for 6 months following an ICD shock. Daily physical activity data were obtained from a built-in device accelerometer.

Results: Average daily activity was $185.3 \pm 119.4$ minutes/day. Activity was significantly reduced after an ICD shock $(\mathrm{p}<0.0001)$ and recovered to a normal level after approximately 90 days. ICD shock was also associated with decreased quality of life (EQ5D Health Score) and increased EQ5D anxiety scores, but it did not impact mobility, self-care, activity, or pain. Similarly, shock anxiety (FSAS) increased in shocked patients and remained significantly elevated at 24 months, regardless of appropriate or inappropriate shock delivery.

Conclusions: ICD shocks have a long-lasting, adverse impact on both objective, devicemeasured physical activity and subjective patient reported outcomes of quality of life and shock anxiety. Successful management of ICD patients requires attention to clinically relevant behavioral and psychological outcomes to expedite recovery and return to activities of daily living. 


\section{Introduction}

The implantable cardioverter defibrillator (ICD) reduces mortality in patients at risk for life-threatening arrhythmias. ${ }^{1}$ However, the fear of experiencing spontaneous arrhythmias and frequent device-delivered shock therapies may lead some patients to limit their daily activities or avoid physical exertion, which could adversely impact their health and quality of life. $^{2}$

Previous studies of health-related quality of life in ICD patients have generally relied on subjective, self-report data that is susceptible to recall bias. Results from these studies have found that while ICD shocks are associated with increased anxiety in smaller, singleinstitution studies, this is not uniformly the case in larger multicenter trials, suggesting a need for improved methodology and precision measurement of the effect of ICD shock on the patient experience. ${ }^{3,4}$ Objective behavioral data associated with ICD shock has also been lacking despite the fact that modern ICDs are capable of collecting longitudinal physical activity data. Device-measured physical activity has been associated with mortality and hospitalization, ${ }^{4-6}$ and could be combined with subjective patient outcomes to provide a more robust examination of the impact of ICD shock on patient activity and quality of life.

In this study, we analyzed data from the PainFree SST clinical trial to prospectively examine the acute and long-term effects of ICD therapies on daily activity, quality of life, and shock anxiety.

\section{Methods}

\section{Study Overview and Patient Population}

PainFree SST was a large multicenter clinical trial designed to evaluate improved device detection algorithms to reduce ICD shock (SmartShock ${ }^{\circledR}$ technology). The study design and primary results have been published elsewhere. ${ }^{7,8}$ In brief, PainFree SST enrolled 2,790 patients from 150 centers worldwide implanted with a Medtronic Protecta ${ }^{\circledR}$ (Medtronic 
plc, Minneapolis, MN, USA) single or dual-chamber ICD, or cardiac resynchronization defibrillator (CRT-D), between September 2009 and August 2012. This included new implants, upgrades, and replacements. Twenty patients were subsequently excluded from all analyses for various reasons, resulting in a final study cohort of 2,770 patients. All patients provided written informed consent. Study protocols and procedures were approved by the ethics committee or institutional review board at all participating sites.

\section{Data Collection}

Patients were seen at enrollment (at the time of ICD implant prior to hospital discharge) and twice annually thereafter. Device data on patient activity and arrhythmia episodes treated with a shock or anti-tachycardia pacing (ATP) were extracted. Available electrocardiograms were reviewed and adjudicated by an independent episode review committee (ERC). Shock anxiety and quality of life data were collected at baseline, bi-annual visits, and monthly for 6 months following an ICD shock. This intensive follow-up approach allowed for closer examination of the immediate and long-term effects of ICD shock from the patient's perspective.

\section{Measures}

Patient activity data were obtained from the internal ICD accelerometer located in the device generator. As the body moves, internal sensors generate an electrical signal that is proportional to acceleration of the generator. A proprietary algorithm interprets the electrical signal and classifies each minute as active or non-active. The algorithm is calibrated to detect walking at a slow pace as active. A daily summary score for total activity in minutes per day is automatically calculated and stored in the device. The use of device-detected accelerometer data has been validated as an objective measure of daily activity in previous studies of ICD patients. , 9-11 $^{-1}$ 
dimension measure of perceived health status (mobility, self-care, usual activities, problems, extreme problems). Additionally, the EQ5D includes a visual analog scale (VAS) which provides a composite health status score referred to as the EQ5D Health Score. Higher EQ5D Health Scores indicate better self-reported health. validated, widely used measure of ICD-specific adjustment that assesses feared stimuli and avoidance behaviors (e.g., "I am scared to exercise because it may increase my heart rate and cause my device to fire"). ${ }^{5}$ Respondents rated items on a five-point scale. Items were summed according to scoring guidelines to obtain a total score ranging from 10 to 50, with higher values indicating greater shock anxiety. FSAS questionnaires were included in the analysis when at least 7 of the 10 questions were answered. For questionnaires with missing answers the summary score was normalized by multiplying with 10/(number of answered questions).

\section{Statistics}

Quality of life was prospectively defined as a secondary objective in PainFree SST.

Activity was later added as an outcome parameter.

For statistical comparison between two groups, a Fisher's exact test or a Cochran-Mantel-

Haenszel test for trend was used. Continuous parameters are presented with mean value and standard deviation, and compared between groups using a Student's t-test. Daily activity records for all patients included device type, time since implant, being hospitalized (yes/no), experienced earlier shocks (yes/no), and time since most recent shock. Analysis of activity used linear mixed regression models with daily values as unit of analysis. 
subsequent measurements from individual patients. A sandwich variance estimator was used as an additional correction for repeated measurements in patients. A base model included device type and time since implant as a piecewise linear covariate with knots at selected timepoints post-implant (30, 60, 90, and 365 days post-implant). Follow-up data were restricted to the first 24 months. Subsequent analyses were done adding variables to the base model. The effect of hospitalization was estimated as the average difference in activity between days hospitalized and days not hospitalized, corrected for device type and time since implant. The effect of ICD shocks was assessed from an indicator variable identifying whether or not there was an earlier shock and a piecewise linear covariate for time since shock with knots at 30, 60 and 90 days post-shock. The effect of ATP was analyzed similarly. Analyses of the effect of shocks and ATP were corrected for device type, time since implant, and the effect of hospitalization. Effects are reported with $95 \%$ confidence intervals (CI).

Analysis of FSAS and EQ5D Health Score used a similar modeling approach with patient visit as the unit of analysis, using a compound symmetry correlation structure. Local regression (LOESS) was used for the figures. Statistical analysis of the different dimensions of EQ5D before and after shock used ordinal logistic regression models with GEE variance adjustment that included all questionnaires from baseline and scheduled follow-up visits with an indicator variable for earlier shocks.

All analyses were done in SAS version 9.4 (SAS Institute, Cary, NC, USA). P-values $<0.05$ were considered significant.

\section{Results}

\section{Baseline Characteristics}

A total of 2,770 patients were followed for $22 \pm 9$ months. Clinical characteristics of the patients are shown in Table 1. ICD shock was more prevalent among patients who were male, implanted for secondary prevention, taking anti-arrhythmic drugs, or had a prior history of 
atrial fibrillation (AF). Compared to patients with only appropriate shocks, patients with any inappropriate shock were more likely to have a history of AF, and less likely to have a history of coronary artery disease, atrioventricular block, coronary artery bypass grafting, or myocardial infarction.

In total, 915 arrhythmic episodes were extracted from device memory, in which 289 patients received ICD shocks ( 0.21 episodes per patient year). This included 804 episodes for which electrocardiograms were available and that were adjudicated: 115 inappropriately shocked episodes in 70 patients and 689 appropriately shocked episodes in 234 patients. Additionally, there were 111 shocked episodes in 17 patients where electrocardiograms were not available due to limited device memory. For 15 of these 17 patients, there were other shocked episodes that had electrocardiograms available. Finally, 19 patients reported ICD shocks only at visits for which no device memory data was available. In total, 308 patients had shocks.

There were 6,017 arrhythmic episodes in 388 patients for which ATP was delivered (1.37 episodes per patient year). There were 1162 hospitalizations in 589 patients reported. Association Between ICD Shock and Physical Activity Daily activity data were available for 2,555 patients. Average daily physical activity was $185.3 \pm 119.4$ minutes per day.

\section{Patient Activity Trends Over Time and the Acute Effects of Shock}

There was a clear rise in physical activity during the first 90 days post-implant $(+88.6$ minutes/day, CI: 85.4 to $91.8, \mathrm{p}<0.0001)$ followed by a gradual decline $(-14.9$ minutes/day between 3 and 24 months, CI: -17.7 to -12.1 , p<0.0001).

Pre-shock activity levels of patients that experienced ICD shock during follow up did not differ significantly from activity levels of patients who did not receive shocks $(193.6 \pm$ 119.4 minutes/day vs $185.8 \pm 119.0$ minutes/day, $\mathrm{p}=0.61$ ). Patients with a CRT-D device 
201

202

203

204

205

206

207

208

209

210

211

212

213

were less active than ICD patients, $164.4 \pm 110.7$ versus $198.4 \pm 122.6$ minutes/day

( $p<0.0001$; see Supplementary Figure S1 for activity values from baseline to 24 months).

Corrected for device type there was no difference between primary and secondary prevention patients. Hospitalization was associated with a significant reduction in daily physical activity (75.3 \pm 84.6 minutes/day in hospital compared to $185.9 \pm 119.2$ minutes/day out of hospital, $\mathrm{p}<0.0001)$

The acute effects of ICD shock on activity are illustrated in Figure 1A. The data show that activity was significantly reduced after an ICD shock (-23.7 minutes/day when corrected for device type, time since implant, and the effect of hospitalization, CI: -30.2 to -17.2 , $\mathrm{p}<0.0001$ ) and recovered as time since shock increased (at 30 days post-shock, activity increased +10.1 minutes/day, CI: 4.1 to $16.0, \mathrm{p}=0.0010$ ). Post-shock activity reduction did not differ significantly between shocks with a hospitalization and shocks without a hospitalization (22.9 minutes/day vs. 19.6 minutes/day; p=0.61, Supplemental Figure 2).

\section{Number of Prior Shocks}

Activity reduction was associated with the number of prior ICD shocks, with 21.1 minutes/day decrease when there was exactly 1 prior shock, 27.4 minutes/day after 2-5 shocks, and 33.8 minutes/day after more than 5 shocks $(\mathrm{p}=0.018)$.

Appropriate vs. Inappropriate Shock

Activity reduction did not differ significantly between appropriate and inappropriate shocks (24.6 minutes/day, CI: 17.9 to 31.2 , vs 20.2 minutes/day, CI: 6.0 to $34.5 ; \mathrm{p}=0.26$, Supplemental Figure 3).

\section{Antitachycardia Pacing (ATP)}

Figure 1B illustrates physical activity in the days before and after low-voltage pacing therapy (ATP). Activity was significantly reduced after ATP (-5.8 minutes/day relative to the 
patient's overall average activity, CI: -11.4 to $-0.13, \mathrm{p}=0.045)$, although the magnitude of the effect is much smaller than for shocks.

227

\section{Association Between ICD Shock and Quality of Life}

Quality of life scores (EQ5D Health Score) before and after ICD shock are shown in Figure 2. Baseline average on the EQ5D Health Score was $66.8 \pm 19.2$. The EQ5D Health Score was lower for CRT-D patients than for ICD patients $(64.8 \pm 19.1$ vs $67.9 \pm 19.2$, $\mathrm{p}<0.0001)$. Corrected for device type, there was no difference between primary and secondary prevention patients and there was also no difference in EQ5D Health Score at baseline between patients that did and did not experience subsequent ICD shock $(67.5 \pm 18.3$ vs $66.7 \pm 19.3 ; \mathrm{p}=0.50)$.

\section{Quality of Life Trends Over Time and the Acute Effects of Shock}

Follow-up Health Score assessments were generally higher than baseline (de novo implants +7.0 points at 12 months; CI: 6.1 to $7.9, \mathrm{p}=0.004$ ), however there were significant decreases during hospitalization (-7.6 points; CI: -10.3 to $-4.9, \mathrm{p}<0.0001)$ and when there had been any earlier shock (-3.6 points; CI: -5.1 to $-2.1, \mathrm{p}<0.0001$, Table 2$)$.

The acute effects of ICD shock on quality of life were also examined by comparing the last assessment before and the first assessment after a patient's first shock episode. These data demonstrated a significant decrease in overall Health Score $(68.2 \pm 19.3$ vs $65.2 \pm 20.5$; $\mathrm{p}=0.029)$. EQ5D subscale scores before and after shock are reported in Supplemental Table 1. Shocks significantly impacted Anxiety/Depression, but not Mobility, Self-Care, Usual Activity, or Pain/Discomfort. Quality of life was also examined monthly for 6 months after the shock event (Figure 4 in the Data Supplement). Post-shock EQ5D Health Score increased as time since shock progressed, signifying improved perceived health $(\mathrm{p}=0.017)$. 
shocks were associated with worse quality of life $(\mathrm{p}=0.01)$. The Health Score was reduced by after $>5$ shocks.

\section{Appropriate vs. Inappropriate Shock}

The decrease in Health Score was seen only after appropriate shocks (-3.9 points; $\mathrm{p}<0.0001)$; there was not a decrease after inappropriate shocks ( -0.9 points; $\mathrm{CI}$ : -3.8 to 2.0 , $\mathrm{p}=0.55)$.

\section{Association Between ICD Shock and Shock Anxiety}

Shock anxiety scores (FSAS scores) before and after ICD shock are presented in Figure 3. At baseline, the average FSAS score was $16.6 \pm 8.0$, comparable to existing norms. ${ }^{5}$ There were no differences between ICD and CRT-D patients, nor between primary and secondary prevention. No baseline differences in FSAS scores were found between patients with and without subsequent shock $(16.9 \pm 7.6$ vs $16.6 \pm 8.0 ; \mathrm{p}=0.69)$.

\section{Shock Anxiety Trends Over Time and the Acute Effects of Shock}

Follow-up FSAS assessments were generally lower than baseline (-2.8 points; CI: -3.1

to $-2.5, \mathrm{p}<0.0001)$ and not different during hospitalization (+1.0 points; $\mathrm{CI}$ : -0.4 to 2.3 , $\mathrm{p}=0.17)$, but were significantly increased when there had been any earlier shock $(+3.2$ points;

CI: 2.6 to $3.7, \mathrm{p}<0.0001$, Table 2).

The acute effects of ICD shock on shock anxiety were examined monthly for 6 months after the shock event (Figure 4). In patients with a prior ICD shock, proximity to the event was significantly associated with FSAS scores, such that greater time since shock was associated with lower FSAS scores and decreased shock anxiety (-0.4 points per months; CI: -0.5 to $-0.3, p<0.0001)$. However, even $>6$ months after the ICD discharge, shock anxiety remained increased (+1.9 points; CI: 1.1 to $2.7, \mathrm{p}<0.0001)$. 
Number of Prior Shocks

The number of prior shocks had a significant impact on the FSAS score $(\mathrm{p}=0.002)$,

FSAS scores increased by 3.3 points when there was 1 prior shock, 2.4 points after 2-5

shocks, and 5.3 points when there were $>5$ prior shocks. A higher number of shocks $(1$ shock vs. $>5$ shocks) was associated with a significant increase in shock anxiety ( $\mathrm{p}=0.0074)$.

\section{Appropriate vs. Inappropriate Shock}

The increase in shock anxiety was larger after appropriate shocks compared to inappropriate shocks (3.3 vs 1.1 points; $\mathrm{p}=0.009$ ), but was not significantly different when the patient was hospitalized (4.6 vs 3.0 points; $\mathrm{p}=0.11$ ).

\section{Discussion}

This study is the first prospective examination of the acute and chronic effects of ICD shock on objective behaviors (i.e. accelerometer detected physical activity) and subjective quality of life outcomes (i.e. self-reported quality of life and shock anxiety) in a large, international cohort of ICD patients. The principal findings from this study are that ICD shock has immediate and long-term adverse effects on global and disease-specific quality of life. Furthermore, baseline device-detected daily physical activity was low in most ICD patients (approximately 3 hours per day) and significantly declined after ICD shock. Activity gradually increased as time since shock progressed and returned to pre-shock levels after approximately 90 days.

By integrating multiple diagnostic parameters to assess quality of life in ICD patients, the current study addresses major limitations of previously published trials. The Sudden Cardiac Death in Heart Failure Trial (SCD-HeFT) demonstrated the deleterious effect of ICD shock on quality of life in the month following a shock using a generic quality of life metric. ${ }^{12}$ Our study extends these findings by describing both the acute and long-term impact of shock on behavioral and psychological recovery in ICD patients. Notably, our analyses 
299

300

301

302

303

304

305

306

307

308

309

310

311

312

313

314

also accounted for device type, ICD indication, device-delivered therapy (shock vs. low voltage pacing), hospitalization, and single vs. multiple ICD shocks. Collectively, these data suggest that declines in quality of life after ICD shock persist beyond 30 days post-shock and may be influenced by significant reductions in daily physical activity, increased general anxiety, and shock anxiety. Generic components of health-related quality of life including mobility, self-care, activity, and pain were not sensitive to these changes, suggesting that shock anxiety and device-based activity data may be more useful measures of ICD-specific outcomes.

The current study builds on earlier work demonstrating the reliability, utility, and significance of device-detected activity data as a prognostic indicator of clinical outcomes. ${ }^{9}$ ${ }^{10,13}$ In a study of heart failure patients with implanted cardiac devices, Cowie et al. found low levels of device-detected activity to be independently associated with a 2.5 -fold increase in risk for hospitalization within the next 30 days. ${ }^{13}$ Additionally, recent data from the ALTITUDE Activity Study demonstrated lower baseline physical activity was associated with a $40 \%$ absolute increase in mortality 4 years after implant. ${ }^{10}$ Low levels of baseline physical activity found in this study (185.3 \pm 119.4 minutes per day) are comparable to activity data reported by Kramer et al. (107.5 \pm 66.2 minutes per day). However, that study did not adjust for hospitalization in their activity analyses and thus, our findings provide important clarification of hospital vs. non-hospital activity data.

Results from the current study also demonstrate the immediate and lasting effects of ICD shock on physical activity and illustrate the significant amount of time (approximately 3 months) it takes patients to return to baseline levels of activity after ICD shock. Given the known associations between low levels of physical activity, psychological functioning, and adverse cardiac events, it is reasonable to assume that ICD patients who experience shock and a prolonged decline in physical activity may have an increased risk for hospitalization, 
morbidity, and mortality. Whether device activity could serve as a behavioral "early warning"

system to prevent adverse outcomes is unknown but potentially viable, and could be

examined in future research.

327

\section{Limitations}

Several limitations should be considered when interpreting these findings. First, the use of self-reported measures is subject to multiple sources of bias including self-presentation bias, the effects of practice or fatigue, and regression to the mean. Second, ICD accelerometers do not provide information concerning activity intensity or type of movement. Third, participants in this study were enrolled in a clinical trial of a single vendor using one brand of ICDs. Moreover, there was no independent validity check on the accelerometer data but such data exists in the literature. ${ }^{11}$ Additionally, our sample included patients from the original Painfree SST trial with new implants, upgrades, and replacements and it is possible that device history or prior shock may have influenced study outcomes. However, we note that $67 \%$ of our sample was de novo implants. Finally, it is possible that the higher frequency of measurement of activity compared to FSAS and EQ5D measurement frequency contributed to the increased sensitivity to capture the effect of a shock.

\section{Conclusions}

This large prospective study of ICD patients demonstrated that ICD shock has immediate and long-term effects on objective and subjective indicators of health, including device measured physical activity, quality of life, and shock anxiety. These results lend further credibility to consideration of patient activity as an important quality of life outcome and support the need for further research and targeted patient and provider interventions to optimize clinical management. 
347 Acknowledgements: We are grateful to Dedra Fagan, of Medtronic, for editorial support.

348

349 Funding: The PainFree SST study was funded by Medtronic plc (Minneapolis, MN). 350 
References

1. Moss AJ, Greenberg H, Case RB, Zareba W, Hall WJ, Brown MW, Daubert JP, McNitt S, Andrews ML, Elkin AD, Multicenter Automatic Defibrillator Implantation Trial IIRG. Long-term clinical course of patients after termination of ventricular tachyarrhythmia by an implanted defibrillator. Circulation Dec 21 2004;110:37603765.

2. Cutitta KE, Woodrow LK, Ford J, Shea J, Fischer A, Hazelton G, Sears SF. Shocktivity: ability and avoidance of daily activity behaviors in ICD patients. J Cardiopulm Rehabil Prev Jul-Aug 2014;34:241-247.

3. Sears SF, Kirian K. Shock and patient-centered outcomes research: is an ICD shock still a critical event? Pacing Clin Electrophysiol Dec 2010;33:1437-1441.

4. Salmoirago-Blotcher E, Ockene IS. Methodological limitations of psychosocial interventions in patients with an implantable cardioverter-defibrillator (ICD) A systematic review. BMC Cardiovasc Disord Dec 29 2009;9:56.

5. Kuhl EA, Dixit NK, Walker RL, Conti JB, Sears SF. Measurement of patient fears about implantable cardioverter defibrillator shock: an initial evaluation of the Florida Shock Anxiety Scale. Pacing Clin Electrophysiol Jun 2006;29:614-618.

6. Sears SF, Whited A, Koehler J, Gunderson B. Examination of the differential impacts of antitachycardia pacing vs. shock on patient activity in the EMPIRIC study. EP Europace 2015;17:417-423.

7. Auricchio A, Meijer A, Kurita T, Schloss E, Brinkman K, Claessens-van Ooijen M, Sterns L. Safety, efficacy, and performance of new discrimination algorithms to reduce inappropriate and unnecessary shocks: the PainFree SST clinical study design. Europace Oct 2011;13:1484-1493.

8. Auricchio A, Schloss EJ, Kurita T, Meijer A, Gerritse B, Zweibel S, AlSmadi FM, Leng CT, Sterns LD, Investigators PS. Low inappropriate shock rates in patients with single- and dual/triple-chamber implantable cardioverter-defibrillators using a novel suite of detection algorithms: PainFree SST trial primary results. Heart Rhythm May 2015;12:926-936.

9. Conraads VM, Spruit MA, Braunschweig F, Cowie MR, Tavazzi L, Borggrefe M, Hill MR, Jacobs S, Gerritse B, van Veldhuisen DJ. Physical activity measured with implanted devices predicts patient outcome in chronic heart failure. Circ Heart Fail Mar 01 2014;7:279-287.

10. Kramer DB, Mitchell SL, Monteiro J, Jones PW, Normand SL, Hayes DL, Reynolds MR. Patient Activity and Survival Following Implantable Cardioverter-Defibrillator Implantation: The ALTITUDE Activity Study. J Am Heart Assoc May 15 2015;4.

11. Vegh EM, Kandala J, Orencole M, Upadhyay GA, Sharma A, Miller A, Merkely B, Parks KA, Singh JP. Device-measured physical activity versus six-minute walk test as a predictor of reverse remodeling and outcome after cardiac resynchronization therapy for heart failure. Am J Cardiol May 01 2014;113:1523-1528.

12. Mark DB, Anstrom KJ, Sun JL, Clapp-Channing NE, Tsiatis AA, Davidson-Ray L, Lee KL, Bardy GH, Sudden Cardiac Death in Heart Failure Trial I. Quality of life with defibrillator therapy or amiodarone in heart failure. N Engl J Med Sep 4 2008;359:999-1008.

13. Cowie MR, Sarkar S, Koehler J, Whellan DJ, Crossley GH, Tang WH, Abraham WT, Sharma V, Santini M. Development and validation of an integrated diagnostic algorithm derived from parameters monitored in implantable devices for identifying patients at risk for heart failure hospitalization in an ambulatory setting. Eur Heart $\mathbf{J}$ Aug 2013;34:2472-2480. 
401

402

403

404

405

406

407

408

409

410

411

412

413

414

415

416 Figure 4. FSAS score decreases when the ICD shock is longer ago, signifying lower anxiety

417 ( $\mathrm{p}<0.0001)$. The horizontal line represents the average FSAS score from scheduled follow-up

418

\section{Figure Legends}

Figure 1. Averaged daily activity in relation to time before or after ICD shock (panel A) or ATP therapy (panel B). The horizontal line represents the overall average activity excluding measurements from the first 90 days post-implant or within 90 days before and 90 days after a shock.

Figure 2. Quality of life (EQ5D Health Score) at scheduled follow-up visits, before and after ICD shock. The horizontal line represents the average Health Score from scheduled followup visits when there was no earlier shock.

Figure 3. Shock anxiety (FSAS scores) before and after ICD shock. The increase of the score after a shock is significant $(\mathrm{p}<0.0001)$, indicating worse shock anxiety following ICD shock. The horizontal line represents the average FSAS score from scheduled follow-up visits when there was no earlier shock.
visits when there was no earlier shock. 
419 Tables

420 Table 1: Patient Characteristics

421

\begin{tabular}{|c|c|c|c|}
\hline Patient Characteristics & $\begin{array}{l}\text { All patients } \\
(\mathrm{N}=\mathbf{2 7 7 0})\end{array}$ & $\begin{array}{c}\text { Any Shock } \\
(\mathbf{N}=308)\end{array}$ & $\begin{array}{c}\text { Inappropriate } \\
\text { Shock } \\
(\mathbf{N}=70)\end{array}$ \\
\hline $\begin{array}{l}\text { Demographics and Clini } \\
\text { Presentation }\end{array}$ & & & \\
\hline \multicolumn{4}{|l|}{ Geography } \\
\hline North America & $1129(41 \%)$ & $93(30 \%)$ & $18(26 \%)$ \\
\hline Europe & $1056(38 \%)$ & $134(44 \%)$ & $28(40 \%)$ \\
\hline Other & $585(21 \%)$ & $81(26 \%)$ & $24(34 \%)$ \\
\hline Male & $2200(79 \%)$ & $265(86 \%)$ & $55(79 \%)$ \\
\hline Age (years) & $65 \pm 12$ & $64 \pm 13$ & $62 \pm 13$ \\
\hline $\operatorname{LVEF}(\%)$ & $32 \pm 13$ & $33 \pm 14$ & $36 \pm 16$ \\
\hline QRS (ms) & $126 \pm 33$ & $128 \pm 33$ & $121 \pm 28$ \\
\hline Secondary prevention & $847(31 \%)$ & $151(49 \%)$ & $23(33 \%)$ \\
\hline \multicolumn{4}{|l|}{ NYHA class } \\
\hline I & $419(15 \%)$ & $58(19 \%)$ & $14(20 \%)$ \\
\hline II & $1104(40 \%)$ & $124(40 \%)$ & $28(40 \%)$ \\
\hline III & $853(31 \%)$ & $85(28 \%)$ & $19(27 \%)$ \\
\hline IV & $38(1 \%)$ & $4(1 \%)$ & $0(0 \%)$ \\
\hline No Heart Failure & $354(13 \%)$ & $36(12 \%)$ & $8(11 \%)$ \\
\hline
\end{tabular}




\begin{tabular}{|c|c|c|c|}
\hline Patient Characteristics & $\begin{array}{l}\text { All patients } \\
(\mathbf{N}=\mathbf{2 7 7 0})\end{array}$ & $\begin{array}{c}\text { Any Shock } \\
(\mathbf{N}=308)\end{array}$ & $\begin{array}{c}\text { Inappropriate } \\
\text { Shock } \\
(\mathbf{N}=70)\end{array}$ \\
\hline \multicolumn{4}{|l|}{ History } \\
\hline Coronary artery disease & $1745(63 \%)$ & $185(60 \%)$ & $30(43 \%)$ \\
\hline Myocardial infarction & $1048(38 \%)$ & $118(38 \%)$ & $14(20 \%)$ \\
\hline Congestive heart failure & $1060(38 \%)$ & $98(32 \%)$ & $19(27 \%)$ \\
\hline Hypertension & $1444(52 \%)$ & $145(47 \%)$ & $35(50 \%)$ \\
\hline Valve dysfunction & $697(25 \%)$ & $83(27 \%)$ & $14(20 \%)$ \\
\hline Coronary artery bypass graft (CABG) & $658(24 \%)$ & $75(24 \%)$ & $8(11 \%)$ \\
\hline Previous device, any & $923(33 \%)$ & $96(31 \%)$ & $22(31 \%)$ \\
\hline \multicolumn{4}{|l|}{ Arrhythmias and Conduction Defects } \\
\hline Atrial fibrillation & $818(30 \%)$ & $119(39 \%)$ & $35(50 \%)$ \\
\hline $\begin{array}{l}\text { Ventricular tachycardia, (incl. non- } \\
\text { sustained) }\end{array}$ & $991(36 \%)$ & $171(56 \%)$ & $37(53 \%)$ \\
\hline AV block & $404(15 \%)$ & $45(15 \%)$ & $2(3 \%)$ \\
\hline Left bundle branch block & $699(25 \%)$ & $75(24 \%)$ & $16(23 \%)$ \\
\hline Right bundle branch block & $215(8 \%)$ & $35(11 \%)$ & $6(9 \%)$ \\
\hline \multicolumn{4}{|l|}{ Device } \\
\hline CRT-D & $1071(39 \%)$ & $113(37 \%)$ & $22(31 \%)$ \\
\hline DR ICD & $948(34 \%)$ & $114(37 \%)$ & $26(37 \%)$ \\
\hline VR ICD & $751(27 \%)$ & $81(26 \%)$ & $22(31 \%)$ \\
\hline
\end{tabular}




\begin{tabular}{|l||c||c||c||}
\hline Patient Characteristics & $\begin{array}{c}\text { All patients } \\
(\mathbf{N}=\mathbf{2 7 7 0})\end{array}$ & $\begin{array}{c}\text { Any Shock } \\
(\mathbf{N}=\mathbf{3 0 8})\end{array}$ & $\begin{array}{c}\text { Inappropriate } \\
\text { Shock } \\
(\mathbf{N}=\mathbf{7 0})\end{array}$ \\
\hline Medication & $2133(77 \%)$ & $240(78 \%)$ & $58(83 \%)$ \\
ACE-inhibitor or ARB & $2370(86 \%)$ & $263(85 \%)$ & $63(90 \%)$ \\
Beta-Blocker & $1886(68 \%)$ & $206(67 \%)$ & $48(69 \%)$ \\
Siuretic & $1673(60 \%)$ & $186(60 \%)$ & $35(50 \%)$ \\
Anti-Arrhythmic & $519(19 \%)$ & $88(29 \%)$ & $13(19 \%)$ \\
\hline \hline
\end{tabular}

422 Numbers are $\mathrm{n}(\%)$ or mean \pm standard deviation.

423 Abbreviations: ACE: angiotensin converting enzyme; ARB: angiotensin receptor blocker;

424 AV: atrio-ventricular; CRT-D: cardiac resynchronization therapy defibrillator; DR-ICD:

425 dual-chamber implantable cardioverter defibrillator; LVEF: left ventricular ejection fraction;

426 NYHA: New York Heart Association; VR-ICD: single chamber implantable cardioverter 427 defibrillator. 
Table 2. The effect of hospitalization and ICD shock on EQ5D Health Score and FSAS

\begin{tabular}{|c|c|c|c|c|}
\hline & $\begin{array}{l}\text { EQ5D Health Score } \\
\text { value / change (CI) }\end{array}$ & p-value & $\begin{array}{c}\text { FSAS } \\
\text { value / change }(\mathrm{CI})\end{array}$ & p-value \\
\hline Baseline ICD patients* & $\begin{array}{ll}65.8 \quad \text { (64.9 to } 66.7) \\
\end{array}$ & & $\begin{array}{ll}17.3 \quad(16.9 \text { to } 17.6) \\
\end{array}$ & \\
\hline CRT-D & $-2.3(-3.5$ to -1.1$)$ & 0.0001 & -- & $(0.10)^{* *}$ \\
\hline Follow-up (12 months)* & $+7.0(6.1$ to 7.9$)$ & $<0.0001$ & $-2.8(-3.1$ to -2.5$)$ & $<0.0001$ \\
\hline In hospital & $-7.6(-10.3$ to -4.9$)$ & $<0.0001$ & & $(0.13)^{* *}$ \\
\hline Earlier shock & $-3.6(-5.1$ to -2.1$)$ & $<0.0001$ & $+3.2(2.6$ to 3.7$)$ & $<0.0001$ \\
\hline
\end{tabular}

430 Abbreviations: CRT-D= Cardiac resynchronization therapy defibrillator; FSAS=Florida

431 Shock Anxiety Scale; ICD=Implantable cardioverter defibrillator

$432 *$ For de novo implanted patients

$433 * *$ Variable removed from final model; $\mathrm{p}$-value from expanded model

434 For example, the average EQ5D Health Score of a CRT-D patient at 12 months after device

435 implantation would be $65.8-2.3+7.0=70.5$. If such patient had a prior shock and was

436 hospitalized, the Health Score would be $(3.6+7.6=) 11.2$ points lower. 
Figure 1A

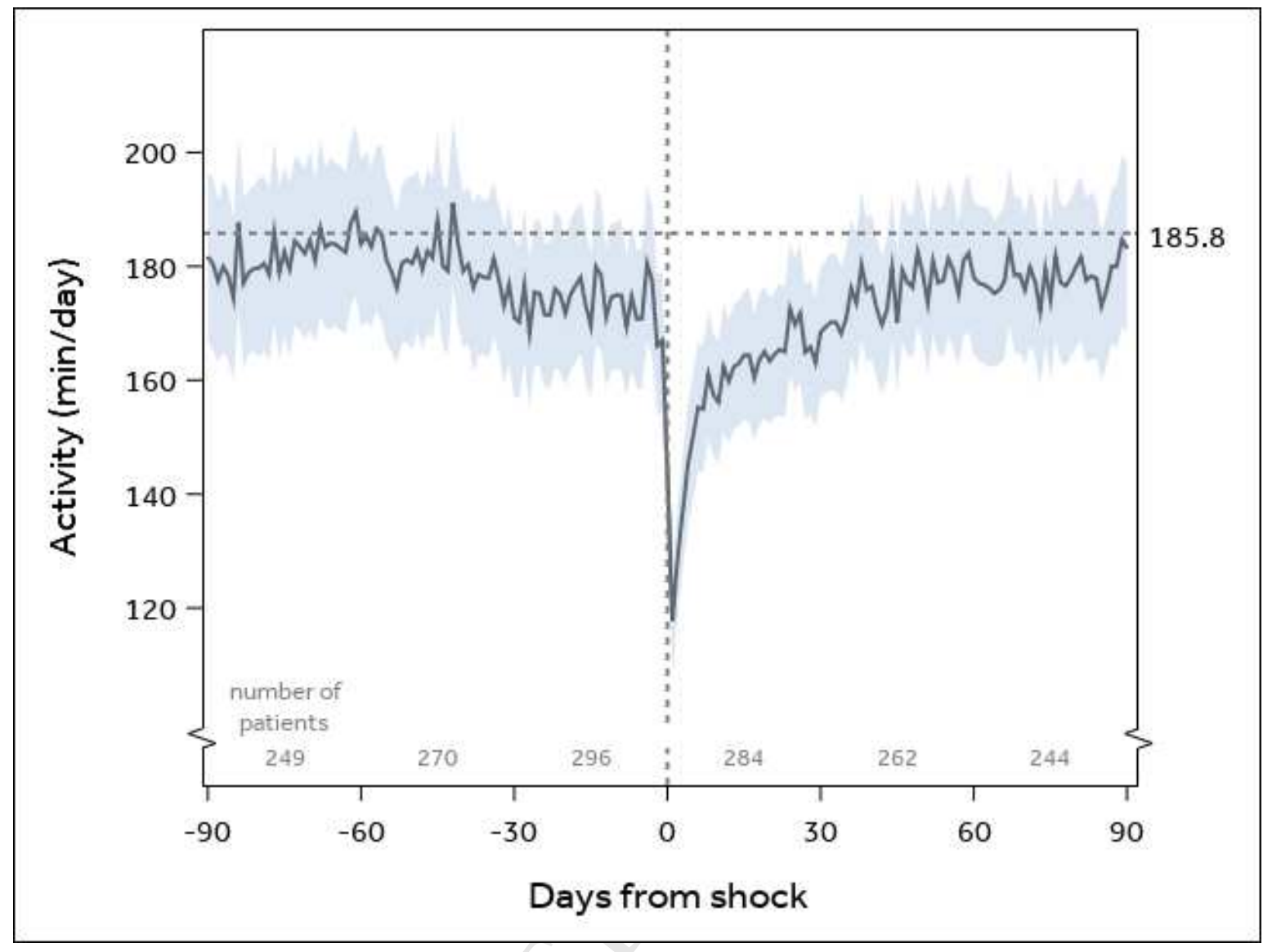


Figure 1B

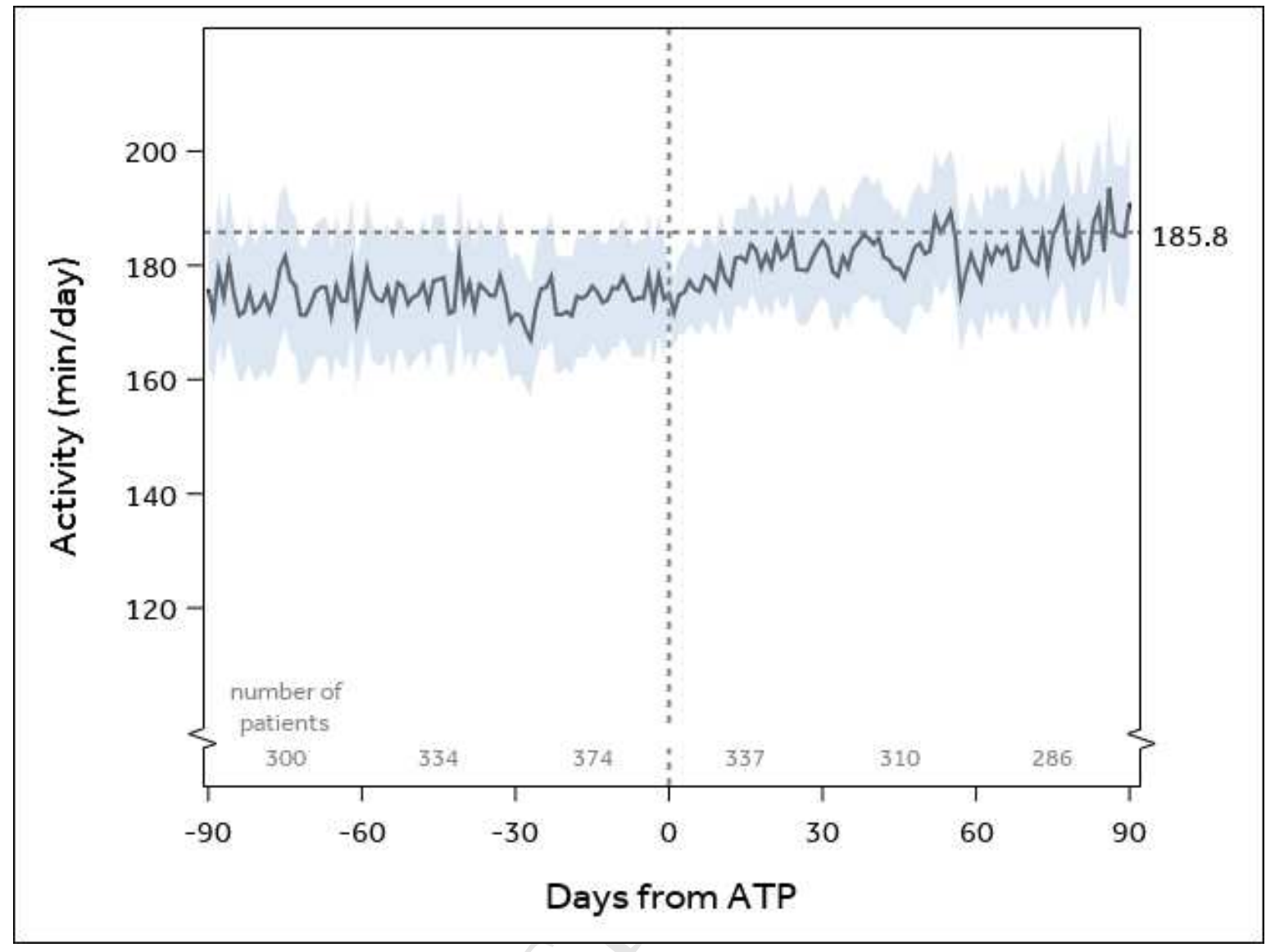


Figure 2

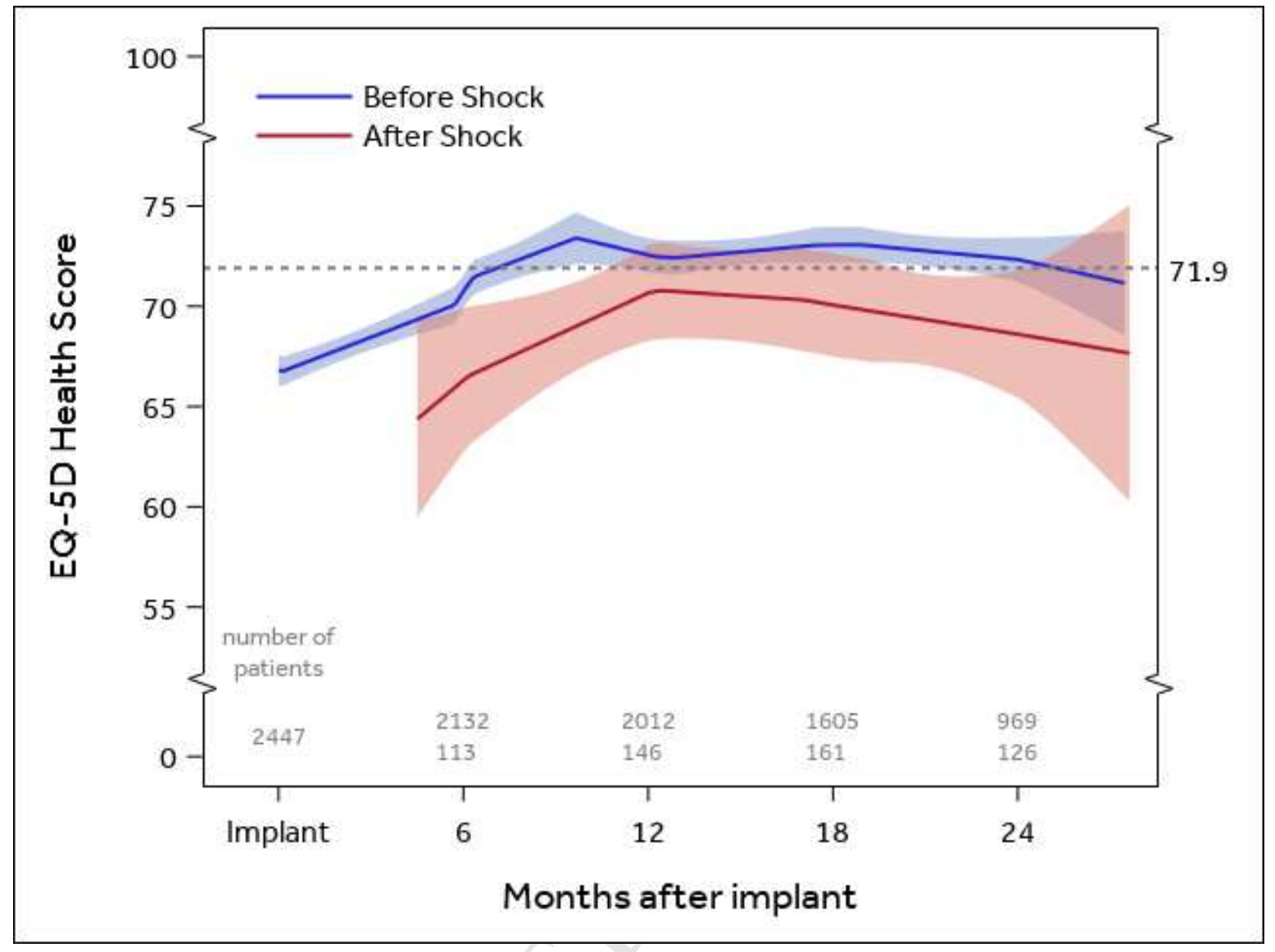


Figure 3

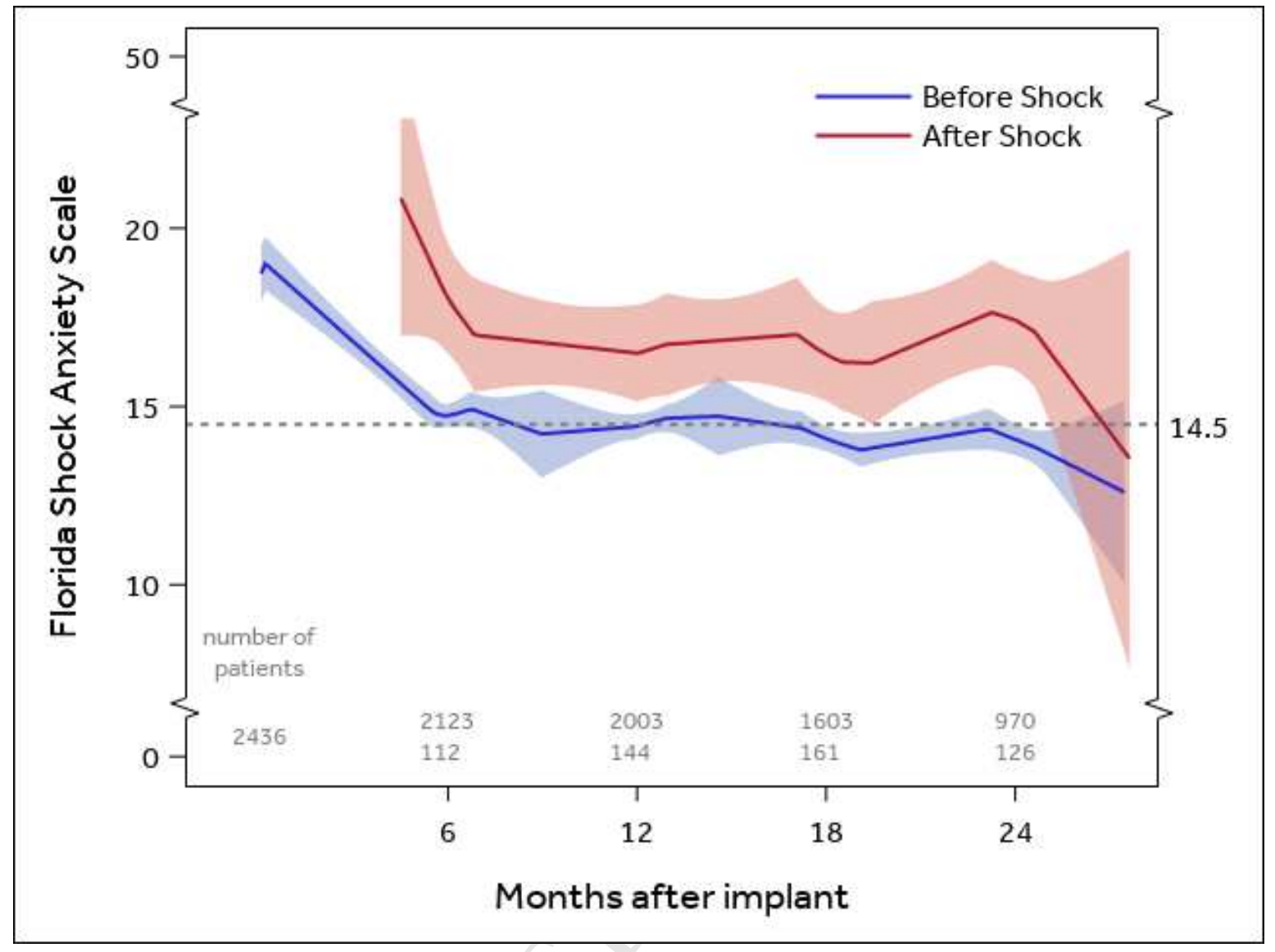


Figure 4

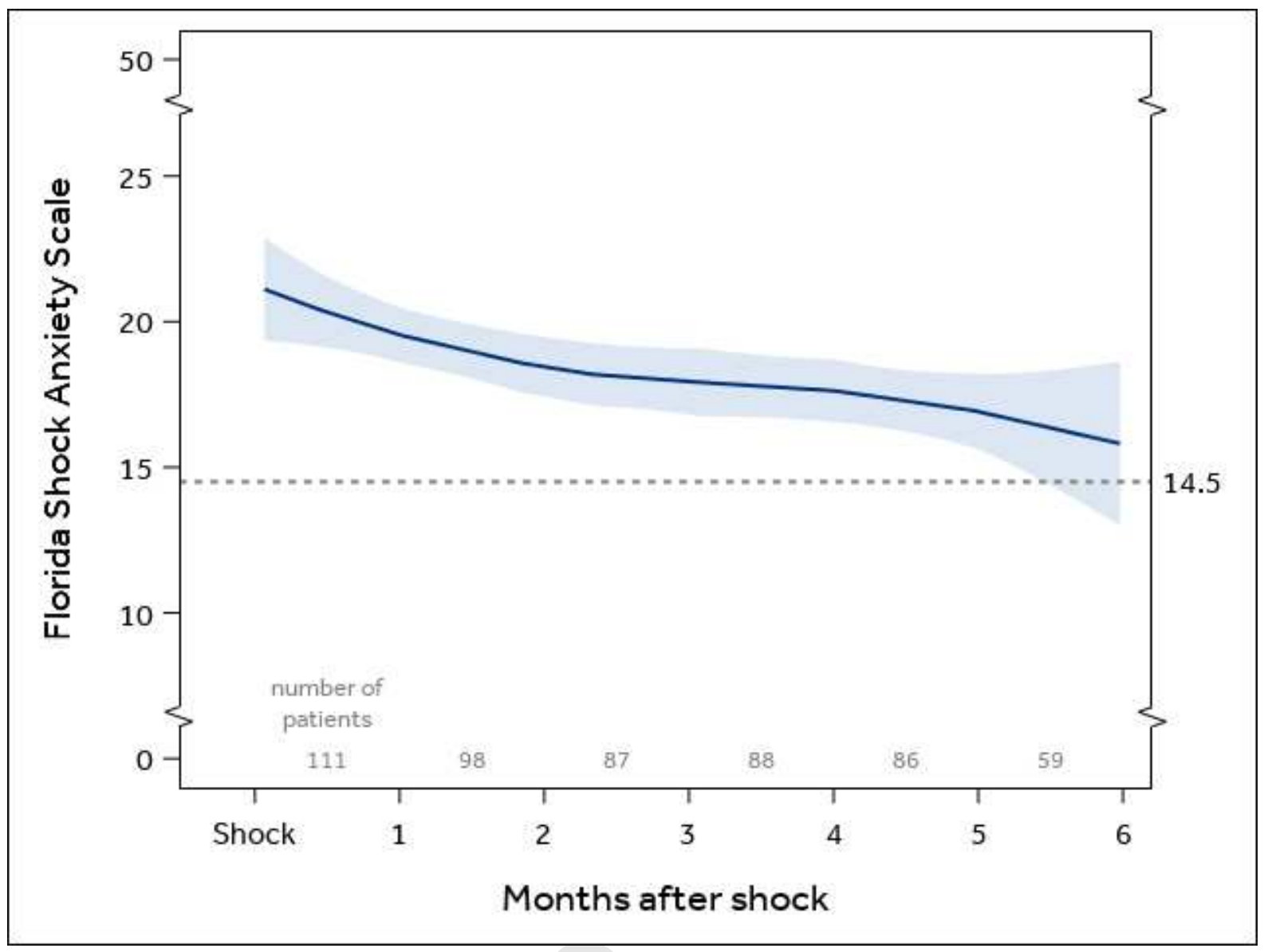

